\title{
Interaction of Wnt Signaling with BMP/Smad Signaling during the Transition from Cell Proliferation to Myogenic Differentiation in Mouse Myoblast-Derived Cells
}

\author{
Kumiko Terada, Satomi Misao, Naoki Katase, \\ Shin-ichiro Nishimatsu, and Tsutomu Nohno \\ Department of Molecular and Developmental Biology, Kawasaki Medical School, Kurashiki, Okayama 701-0192, Japan \\ Correspondence should be addressed to Tsutomu Nohno; nohno@bcc.kawasaki-m.ac.jp
}

Received 27 April 2013; Accepted 3 June 2013

Academic Editor: Michael Peter Sarras

Copyright (c) 2013 Kumiko Terada et al. This is an open access article distributed under the Creative Commons Attribution License, which permits unrestricted use, distribution, and reproduction in any medium, provided the original work is properly cited.

\begin{abstract}
Background. Wnt signaling is involved in muscle formation through $\beta$-catenin-dependent or -independent pathways, but interactions with other signaling pathways including transforming growth factor $\beta /$ Smad have not been precisely elucidated. Results. As Wnt4 stimulates myogenic differentiation by antagonizing myostatin (GDF8) activity, we examined the role of Wnt4 signaling during muscle differentiation in the $\mathrm{C} 2 \mathrm{C} 12$ myoblast cell line. Among several extrinsic signaling molecules examined in a microarray analysis of $\mathrm{C} 2 \mathrm{C} 12$ cells during the transition from cell proliferation to differentiation after mitogen deprivation, bone morphogenetic protein 4 (BMP4) expression was prominently increased. Wht4 overexpression had similar effects on BMP4 expression. BMP4 was able to inhibit muscle differentiation when added to the culture medium. BMP4 and noggin had no effects on the cellular localization of $\beta$-catenin induced by Wnt3a; however, the BMP4-induced phosphorylation of Smad1/5/8 was enhanced by Wnt4, but not by Wnt3a. The BMP antagonist noggin effectively stimulated muscle differentiation through binding to endogenous BMPs, and the effect of noggin was enhanced by the presence of Wnt3a and Wnt4. Conclusion. These results suggest that BMP/Smad pathways are modified through Wnt signaling during the transition from progenitor cell proliferation to myogenic differentiation, although Wnt/ $\beta$-catenin signaling is not modified with BMP/Smad signaling.
\end{abstract}

\section{Background}

The Wnt and transforming growth factor (TGF) $\beta$ signaling pathways have gained attention as potential therapeutic targets for cancer treatment and research interests in regenerative medicine and stem cell biology, because these extrinsic signals are implicated in cell fate determination [14]. The signaling interaction between the Wnt family and the TGF $\beta$ superfamily during morphogenetic processes in most animal embryos has been debated by developmental biologists [2-5]. At an initial step of axial determination, bone morphogenetic proteins (BMPs), members of the transforming growth factor- $\beta$ (TGF- $\beta$ ) superfamily, and Wnt family members have been recognized as key mediators involved in the formation of the dorsal/ventral axis and the anterior/posterior axis, in addition to the fibroblast growth factor family and the hedgehog family $[5,6]$. BMPs are known to regulate the proliferation, differentiation, and apoptosis of various types of cells during embryonic development and postnatal turnover or regeneration. The formation of skeletal muscle from paraxial mesoderm is influenced by signals from the neural tube and the dorsal ectoderm, including Wnt 4 and BMP4, and by the determination of myogenic cell fate by intrinsic factors including $M y o D$ and $M y f 5[7,8]$. In adult skeletal muscle, satellite cells proliferate and differentiate during myotube turnover through signaling by Wnt family members $[9,10]$.

Mesenchymal stem cells are known sources of osteogenic and myogenic progenitor cells. The Wnt and BMP signaling pathways play key roles in stem cell maintenance and adult tissue homeostasis and in the commitment of mesenchymal stem cells to osteogenic or myogenic progenitor cell fates $[7,8]$. Myogenic cell fate is determined by intrinsic and extrinsic signals, and the role of Wnt 4 in myostatin-regulated 
muscle formation has been debated because Wnt 4 signaling is independent of $\beta$-catenin signaling [11-16]. Although the commitment of mesenchymal progenitor cells to myoblast fate is known to be modulated through TGF $\beta$ superfamily members including myostatin, the role of Wnt signaling was only evaluated in a preliminary fashion with respect to signaling interactions [7-9].

Mouse myoblast-derived $\mathrm{C} 2 \mathrm{C} 12$ cells can differentiate into myotubes under reduced mitogen conditions with low serum concentration. We used microarray analysis to determine the expression profile of $\mathrm{C} 2 \mathrm{C} 12$ cells during myoblast differentiation. BMP4 expression is upregulated after Wnt4 overexpression and mitogen deprivation in $\mathrm{C} 2 \mathrm{C} 12$ myoblast cells. We examined possible interactions between Wnt4 and BMP4 with respect to myogenic differentiation and found that BMP4/Smad signaling was affected by Wnt signaling during differentiation of myogenic progenitor cells.

\section{Results}

2.1. Wnt4-Overexpressing Cell Lines from C2C12 and Transcriptome Analysis. Mouse mesenchymal myogenic progenitor $\mathrm{C} 2 \mathrm{C} 12$ cells can differentiate into myotubes after serum starvation under low-serum conditions. When a plasmid construct expressing Wnt4 under control of the CMV promoter-enhancer was used to transfect C2C12 cells, we obtained several cell lines stably expressing Wnt4 from the transfectants after several passages in the selection medium. Three cell lines named W4-02, W4-03, and W4-08, out of 14 candidate cell lines, were used for further studies. All of these cell lines showed a reduced rate of proliferation in rich medium, down to about half of the rate of the parental C2C12 cells. Although the expression level of Wnt4 protein was not high enough to be detected with anti-V5 antibodies, we detected Wnt4 mRNA in these cell lines by reverse transcription PCR with Wnt4 primers (data not shown). When cultured in the proliferation medium and the differentiation medium containing $10 \%$ fetal bovine serum and $2 \%$ horse serum, respectively, these cells were able to differentiate spontaneously, as indicated by myosin heavy chain expression (MyHC) and a reduced number of cells (Figure 1). The parental $\mathrm{C} 2 \mathrm{C} 12$ cells expressed MyHC very infrequently and proliferated more rapidly than the Wnt4expressing cells.

When the total gene expression pattern was analyzed by hybridization with a mouse $24 \mathrm{k}$ cDNA microarray for transcriptome analysis, we found that the expression of the target genes involved in cell differentiation increased significantly during myoblast differentiation after the transition to the low-mitogen condition and Wnt4 overexpression. Besides intrinsic signals related to myogenic differentiation, such as MyoD1, myf5, and mrf4, BMP4 expression was elevated after Wnt4 overexpression. Clustering analysis between $\mathrm{C} 2 \mathrm{C} 12$ in proliferation medium $(\mathrm{C} 2 \mathrm{C} 12-\mathrm{PR})$ and $\mathrm{C} 2 \mathrm{C} 12$ in differentiation medium (C2C12-DF) or W4-08 in proliferation medium (C2C12-W4-08) showed that thousands of genes were commonly upregulated or downregulated (Figure 2). The myogenin gene was upregulated in $\mathrm{C} 2 \mathrm{C} 12-\mathrm{DF}$, whereas the Myf5 gene was upregulated in $\mathrm{C} 2 \mathrm{C} 12-\mathrm{W} 4-08$, suggesting that serum starvation-induced myogenic differentiation and Wnt4-induced myogenic differentiation use overlapping but not identical signaling pathways. In Wnt4-expressing cells, 1477 differentiation-induced genes were also upregulated (Figure 2), including Postn, Kif7, Kitl, Il2ra, Wnt4, Bmp4, Dcn, Cox6a2, Nov, Ogn, and Aspn (See Supplementary 1 in the Supplementary Material available online at http://dx.doi.org/10.1155/2013/616294). On the other hand, 1834 differentiation-reduced genes were also downregulated in Wnt4-expressing cells (Figure 2), including Mrpplf4, Jam4, Prkch, Nefl, Art3, Lrrn6c, Dlx3, Cd83, Ntsr2, Osbp2, Kpna4, E2f8, and Cck (Supplementary 1). Among these upregulated genes, BMP4 is known to act as an extrinsic factor through autocrine or paracrine mechanisms to regulate cell differentiation through transmembrane receptors [17], and its elevated expression suggests the involvement of BMP signaling during myogenic differentiation. We therefore evaluated the effects of $\mathrm{BMP} 4$ protein on $\mathrm{C} 2 \mathrm{C} 12$ differentiation.

2.2. Effects of BMP4 and Noggin on Myogenic Differentiation. When recombinant BMP4 protein was added to the culture medium, it had negative effects on the myogenic differentiation of progenitor cells, indicated by troponin $\mathrm{T}$ expression (Figure 3 ), as previously observed with myostatin, TGF $\beta$, and BMP2 [18-20]. We used troponin T expression instead of $\mathrm{MyHC}$ expression hereafter because troponin $\mathrm{T}$ is expressed much earlier than $\mathrm{MyHC}$ in $\mathrm{C} 2 \mathrm{C} 12$ cells even in the proliferation medium. The inhibitory effects of BMP4 addition to the culture medium on myogenic differentiation were blocked by noggin, and noggin itself promoted the differentiation of C2C12 cells (Figure 3). Smad1/5 phosphorylation induced by BMP4 was also inhibited by noggin, indicating an antagonistic activity of noggin at the level of BMP4 binding to the receptor complex (Figure 4). BMP4 showed negative effects on $\mathrm{C} 2 \mathrm{C} 12$ differentiation, as indicated by the number of troponin T-expressing cells and of cells fusing to form multinuclear myotubes (Figure 3). The addition of noggin affected cell shape and promoted cell proliferation and differentiation, possibly by counteracting the effects of endogenous BMPs.

2.3. Wnt3a and Wnt4 Affect BMP4-Dependent Smad Signaling. The effects of BMP4 and noggin on phospho-Smad1/5 expression were examined in the presence or absence of Wnt3a and Wnt4. Wnt3a either synergizes with or opposes the effects of Wnt 4 on myogenic differentiation, depending on the $\mathrm{C} 2 \mathrm{C} 12$ cellular context (Figures 5 and 6 ). When BMP4 was added in combination with Wnt3a and/or Wnt4, C2C12 differentiation into troponin T-expressing cells in the proliferation medium was markedly inhibited, and the inhibitory effects were most evident in the presence of Wnt3a and Wnt4 (Figure 5). On the other hand, noggin stimulated myogenic differentiation, as indicated by enhanced expression of troponin $\mathrm{T}$ (Figure 6). The stimulatory effects on troponin $\mathrm{T}$ expression were most remarkable in the presence of Wnt3a and Wnt4 (Figure 6). Thus, the Wnt family members modulated myogenic differentiation through a positive 


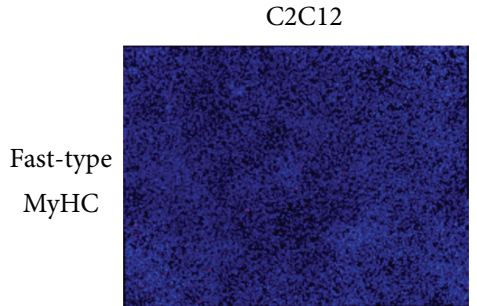

(a)

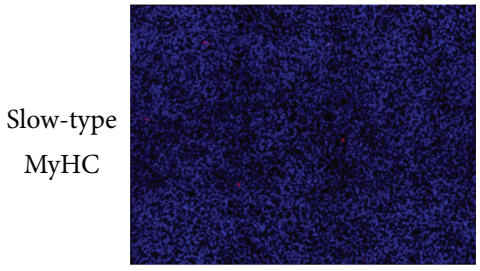

(b)
W4-08

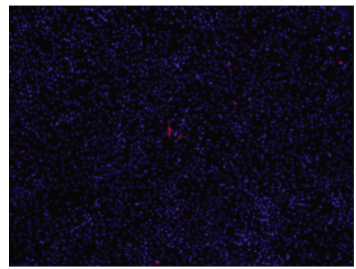

(c)

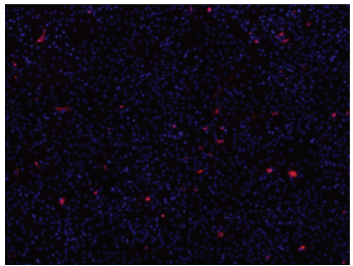

(d)
$\mathrm{C} 2 \mathrm{C} 12$

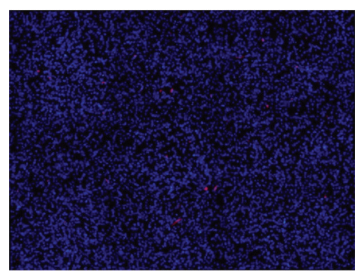

(e)

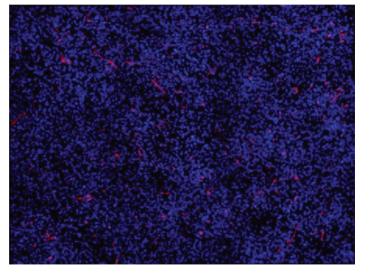

(f)

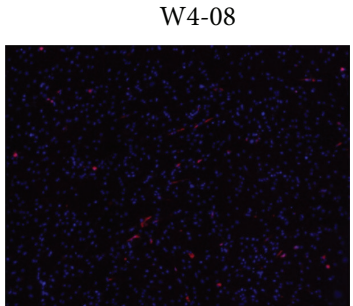

(g)

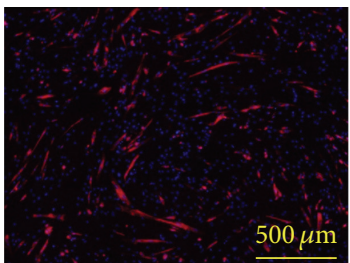

(h)

FIGURE 1: Myosin heavy chain (MyHC) expression in parental C2C12 cells and C2C12-derived cells permanently expressing Wnt4. Parental $\mathrm{C} 2 \mathrm{C} 12$ cells ( $\mathrm{a}, \mathrm{b}, \mathrm{e}$, and $\mathrm{f}$ ) and W4-08 cells ( $\mathrm{c}, \mathrm{d}, \mathrm{g}$, and $\mathrm{h}$ ) were cultured for 2 days in proliferation medium containing $10 \%$ fetal bovine serum (a-d), or in differentiation medium containing $2 \%$ horse serum $(\mathrm{e}-\mathrm{h})$, and then immunohistochemically stained with anti-MyHC antibodies, followed by counterstaining with DAPI. Spontaneous expression of slow-type MyHC was evident in W4-08 cells in proliferation medium and intensified in differentiation medium, although the proliferation rates were greatly reduced compared to those of the parental C2C12 cells, as observed in the reduced number of nuclei (blue).

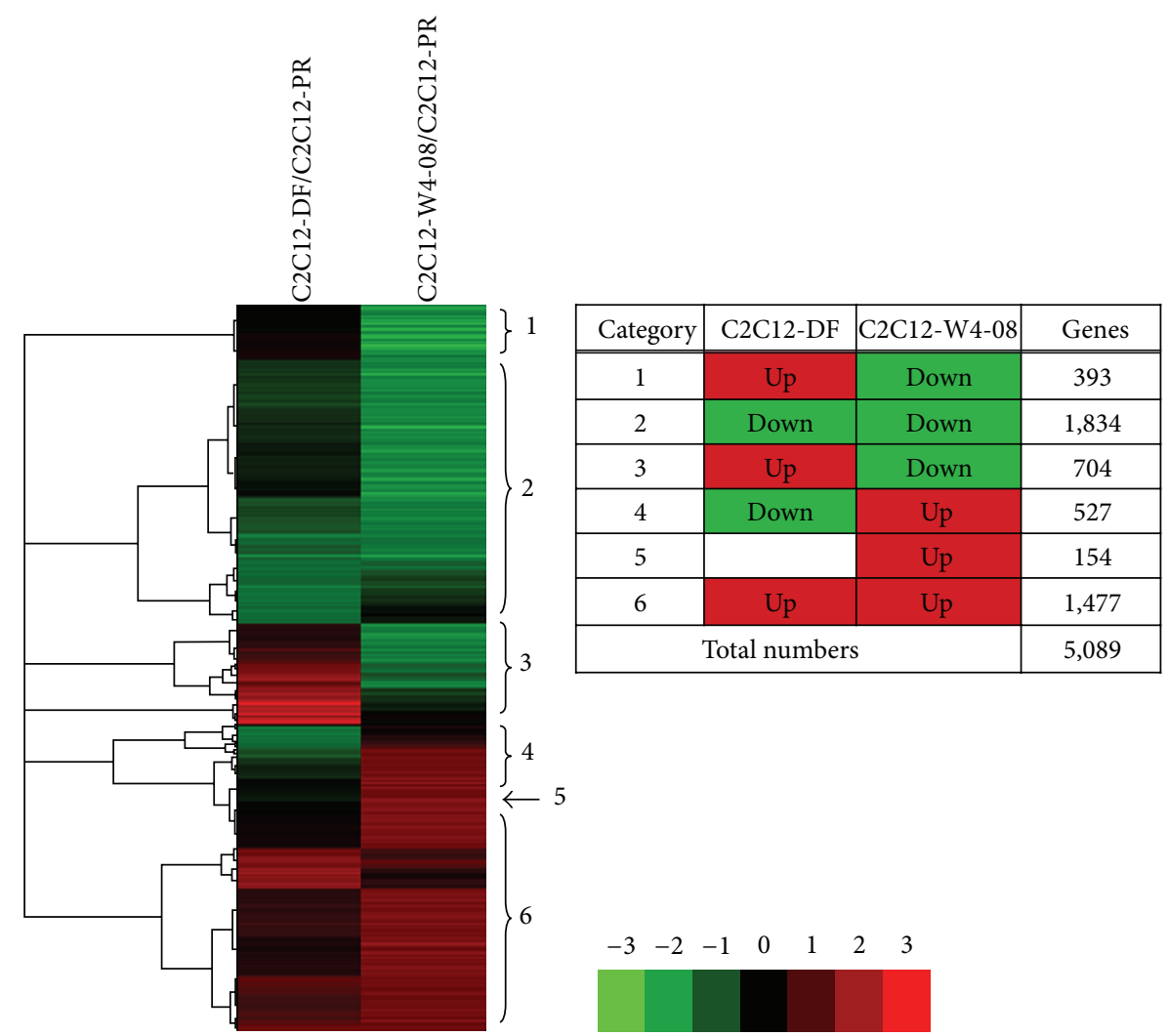

FIGURE 2: Summary of expression array analysis for C2C12 differentiation and Wnt4 expression. Red and green colors show upregulated and downregulated expression, respectively, with differentiation medium and Wnt4 overexpression. 1477 and 1836 genes were upregulated and downregulated, respectively, in differentiation medium and Wnt4 overexpression at a twofold magnitude. Refer to original data in supplementary 1 for details. 


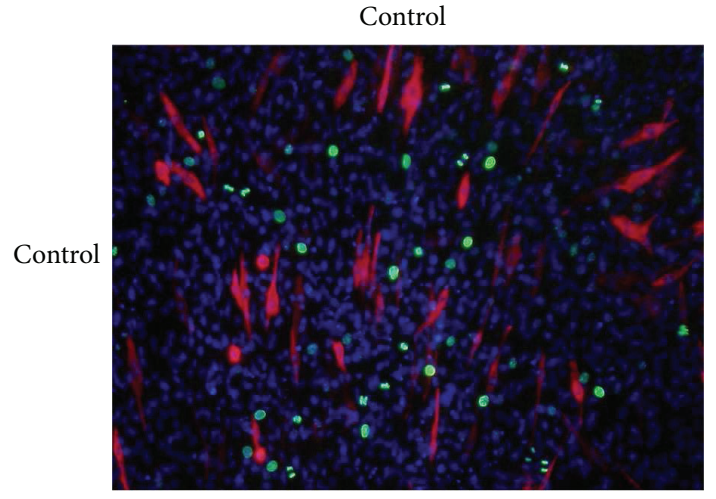

(a)

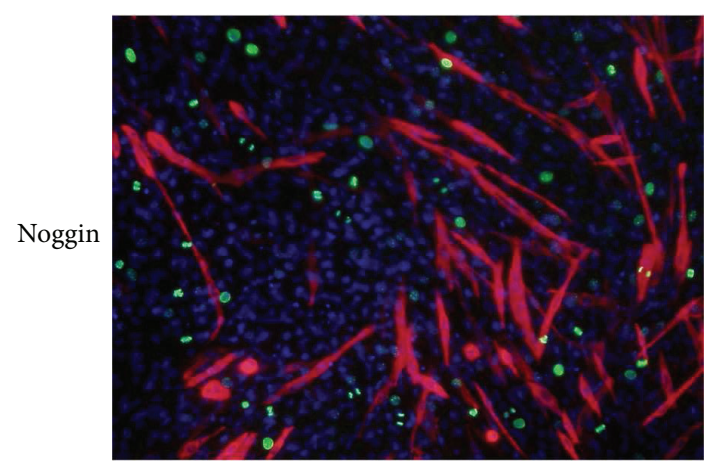

(b)

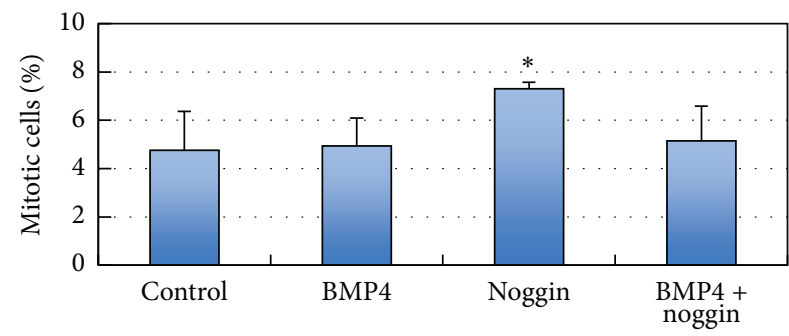

(e)
BMP4

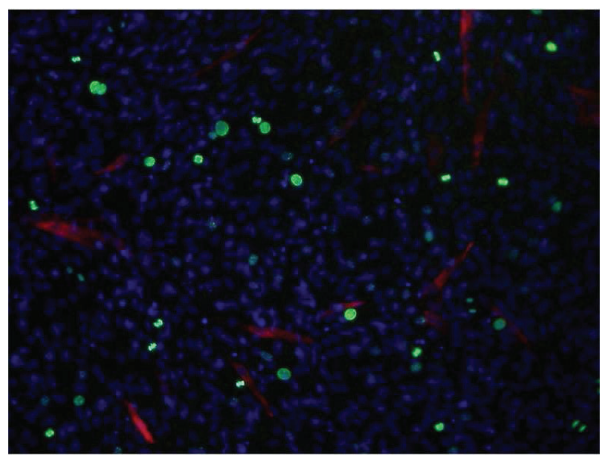

(c)

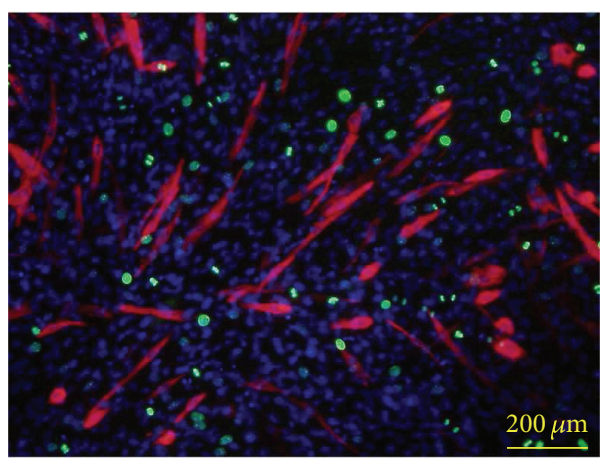

(d)

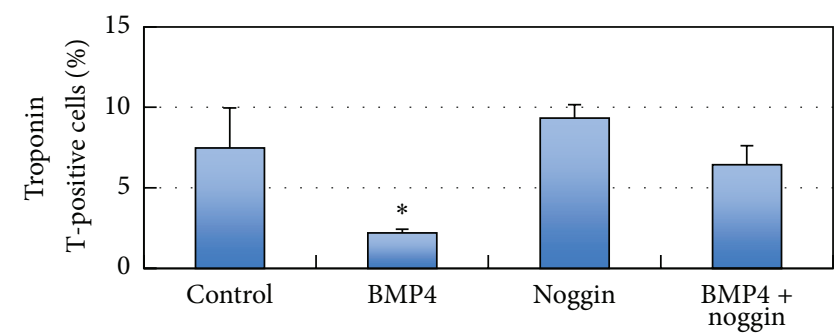

(f)

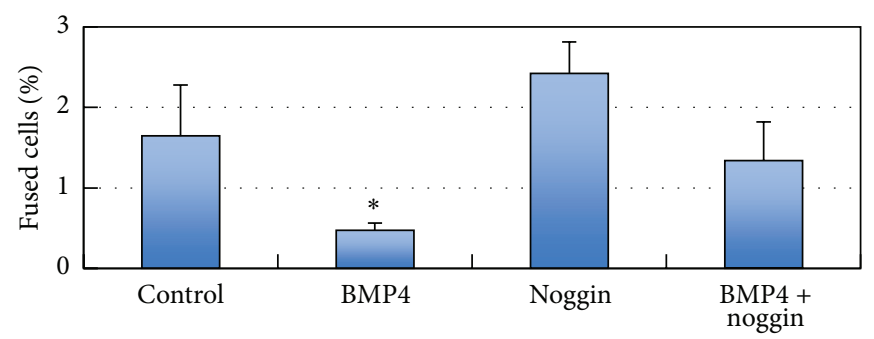

(g)

FIGURE 3: Effect of BMP4 and noggin on the myogenic differentiation of $\mathrm{C} 2 \mathrm{C} 12$ cells. (a-d) The recombinant proteins were added to the proliferation medium at final concentrations of $5 \mathrm{ng} / \mathrm{mL}$ BMP 4 and/or $50 \mathrm{ng} / \mathrm{mL}$ noggin and cultured in proliferation medium for 3 days, followed by immunostaining with anti-troponin T antibodies (red) and anti-phosphohistone H3 (Ser10) antibodies (green). BMP4 addition inhibited myogenic differentiation in proliferation medium. The number of cells expressing phosphorylated histone H3 was increased by adding noggin but not BMP4. (a) Control; (b) noggin; (c) BMP4; (d) noggin + BMP4. (e-g) The ratios of phosphohistone H3 (e) and troponin T-positive cells (f) to the total cell number were estimated. The number of multinuclear cells expressing troponin $\mathrm{T}$ (g) was also estimated to determine the ratio of fused cells among the total cells. Mean $+\mathrm{SD}(n=3),{ }^{*} P<0.05$ versus control with Student's $t$-test. 


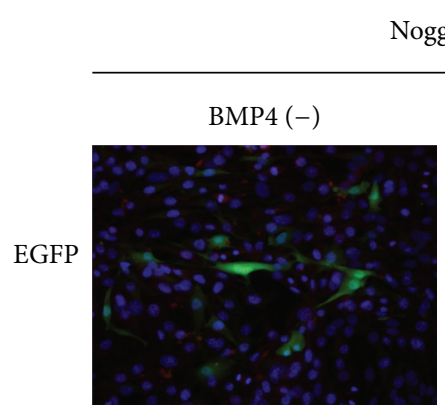

(a)

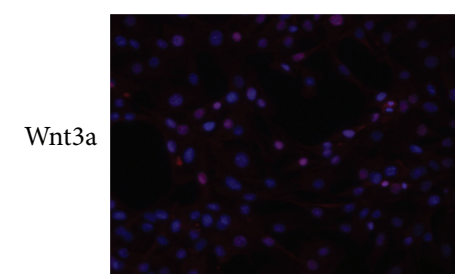

(b)

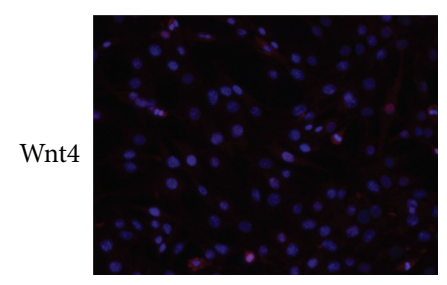

(c)
Noggin (-)

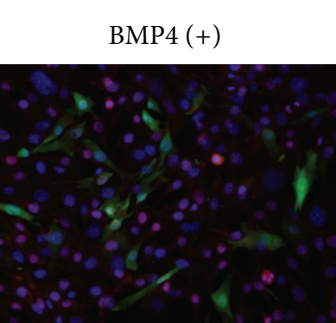

(d)

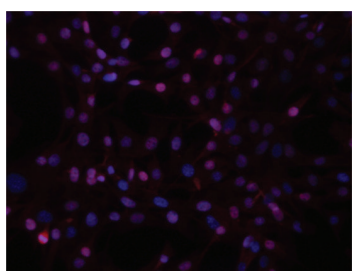

(e)

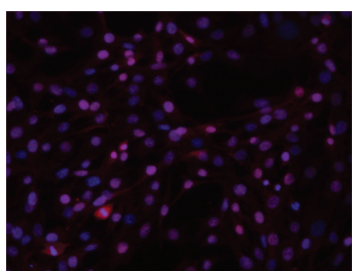

(f)
Noggin (+)

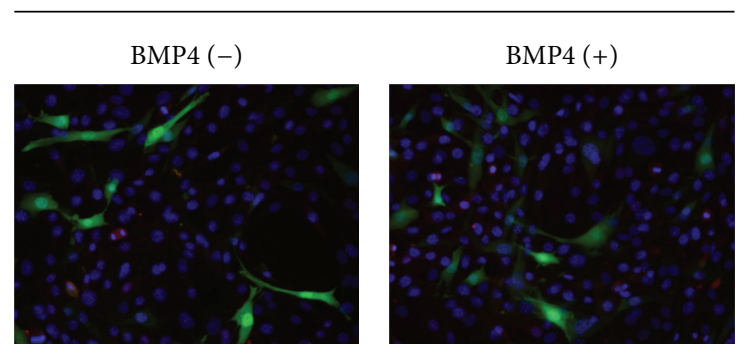

(g)

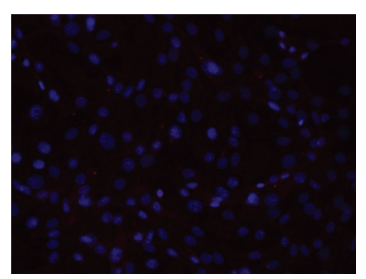

(h)

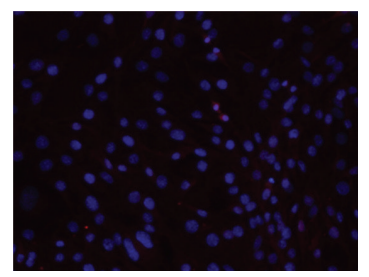

(i) (j)

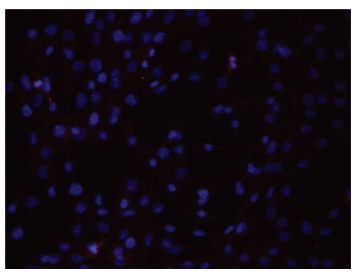

(k)

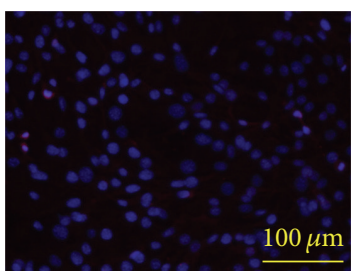

(1)

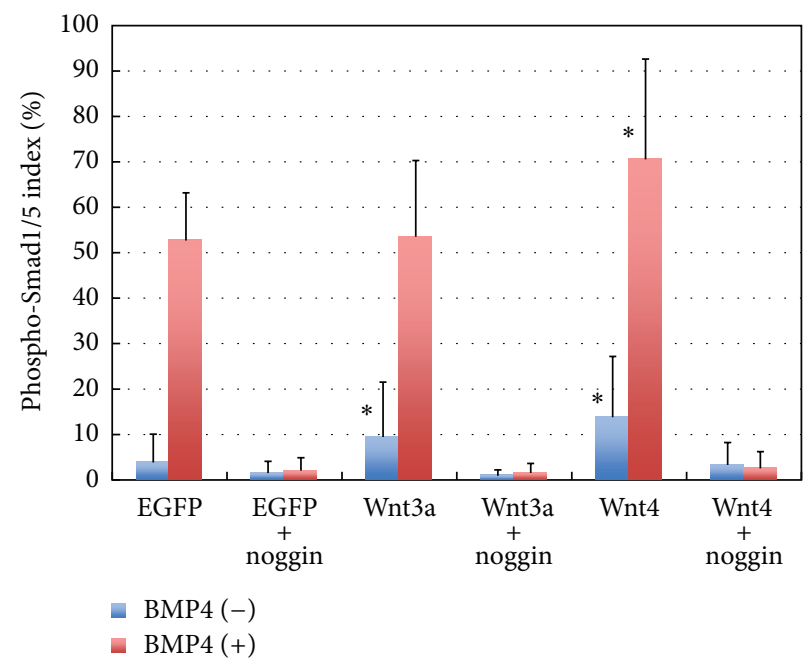

(m)

FIGURE 4: Effects of BMP4 and noggin on phospho-Smad1/5 expression with or without Wnt3a and Wnt4. (a-1) Recombinant adenoviruses were used to express Wnt $3 a$, Wnt4, or eGFP (control) uniformly in C2C12 cells. Cells were infected 48 hours earlier with an MOI of 400, and the recombinant proteins were added as shown in Figure 3 with final concentrations of $5 \mathrm{ng} / \mathrm{mL}$ BMP4 and/or $250 \mathrm{ng} / \mathrm{mL}$ noggin. Two hours after BMP4 addition, immunostaining for phospho-Smad1/5 was carried out for counting. (a-c) Control; (d-f) BMP4; (g-i) noggin; ( $\mathrm{j}-\mathrm{l}$ ) BMP4 + noggin. $(\mathrm{m})$ The ratio of the nuclear phospho-Smad1/5-positive cells to the total cell number was estimated in three independent experiments counted for 6 fields each (mean $+\mathrm{SD}, n=18,{ }^{*} P<0.05$ with Student's $t$-test).

influence on BMP4/Smad signaling (Figure 4). The effects of BMP4 on phospho-Smad1/5 expression were modified by Wnt4 but not by Wnt3a (Figure 4), although Wnt3a and Wnt4 both effectively stimulated basal and endogenous Smad1/5 signaling in $\mathrm{C} 2 \mathrm{C} 12$ cells (Figure 4).
2.4. Wnt3a-Induced $\beta$-Catenin Localization Is Not Influenced by BMP4 and Noggin. Here, we used recombinant adenoviruses expressing Wnt3a and Wnt4 instead of the recombinant proteins, because the subcellular localization and detection of $\beta$-catenin were much easier with a low but 
Control

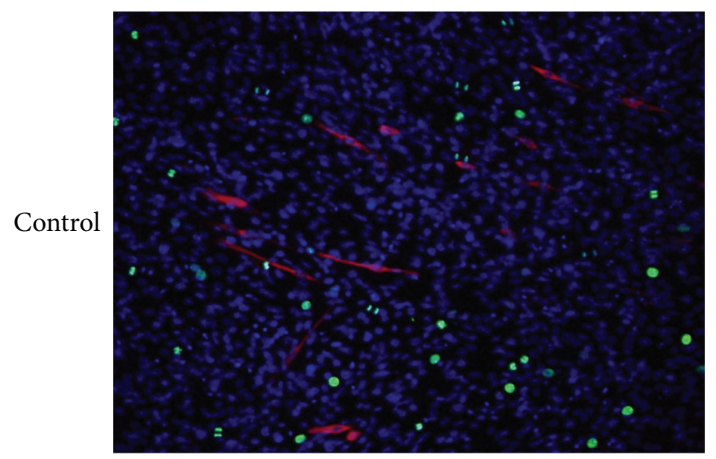

(a)

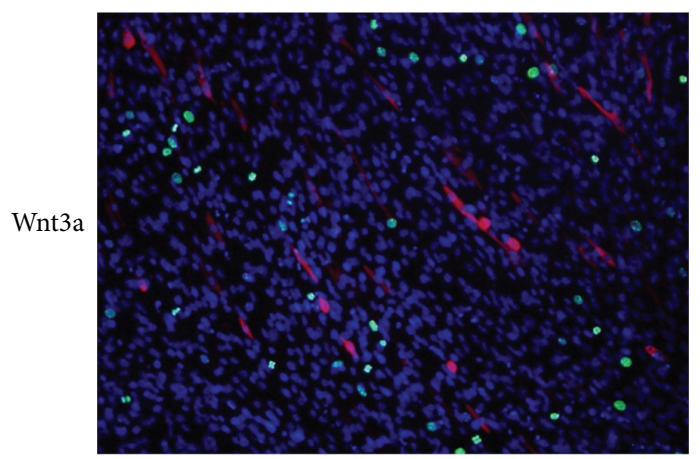

(b)

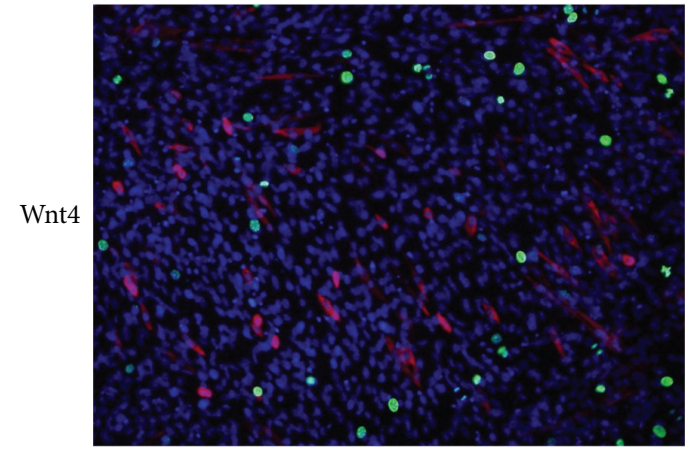

(c)

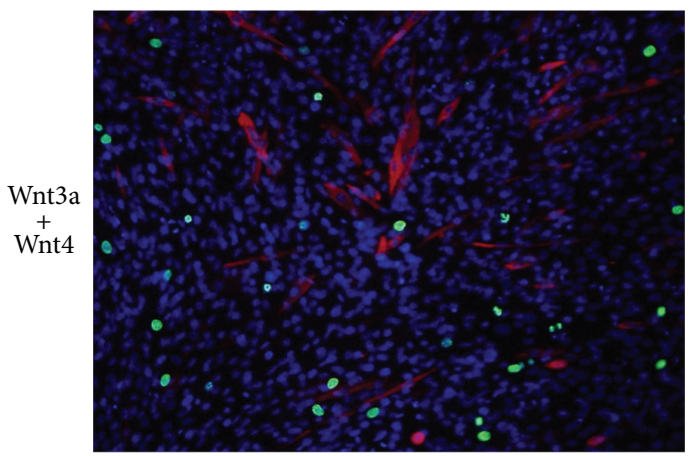

(d)
BMP4

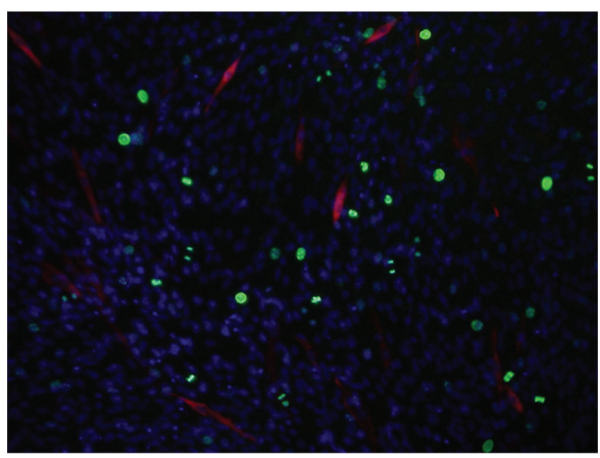

(e)

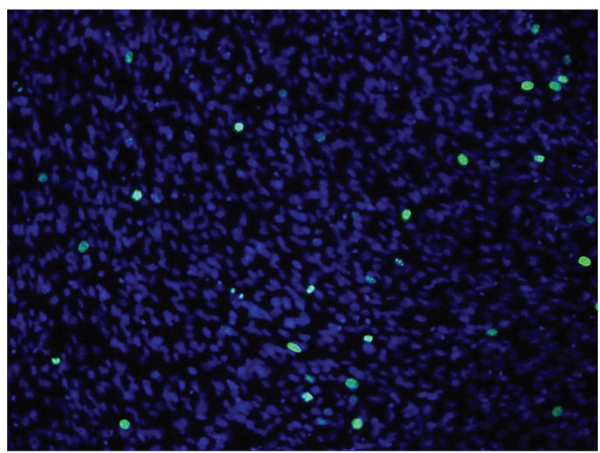

(f)

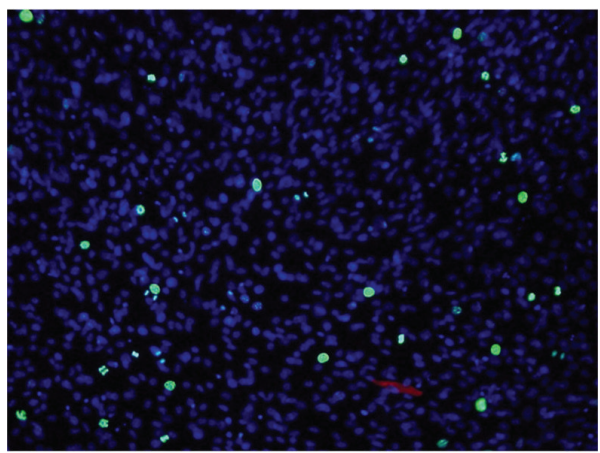

(g)

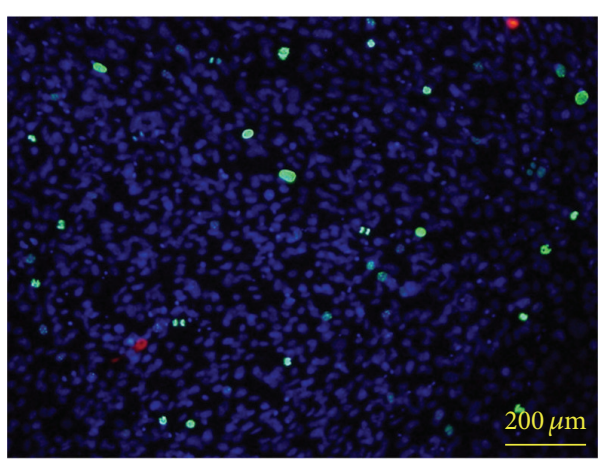

(h)

FIGURE 5: Effect of BMP4 on troponin T expression with or without Wnt3a and Wnt4. (a-h) The recombinant proteins were added as shown in Figure 3 with final concentrations of $125 \mathrm{ng} / \mathrm{mL}$ Wnt $3 \mathrm{a}, 250 \mathrm{ng} / \mathrm{mL}$ Wnt 4 , and $5 \mathrm{ng} / \mathrm{mL} \mathrm{BMP} 4$, alone or in combination as shown in the figure. Immunostaining and cell counting were carried out as described in Figure 3. Addition of BMP4 entirely abolished troponin T expression in the presence or absence of Wnt3a and/or Wnt4. (a) Control; (b) Wnt3a; (c) Wnt4; (d) Wnt3a + Wnt4; (e) BMP4; (f) Wnt3a + BMP4; (g) Wnt4 + BMP4; (h) Wnt3a + Wnt4 + BMP4. 


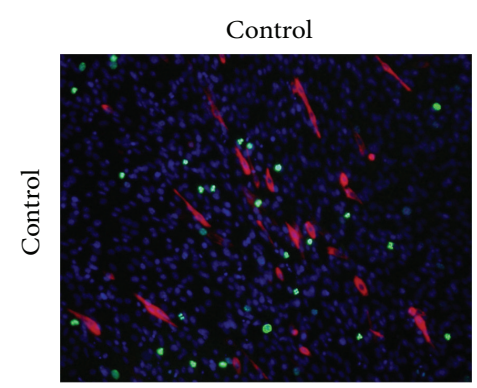

(a)

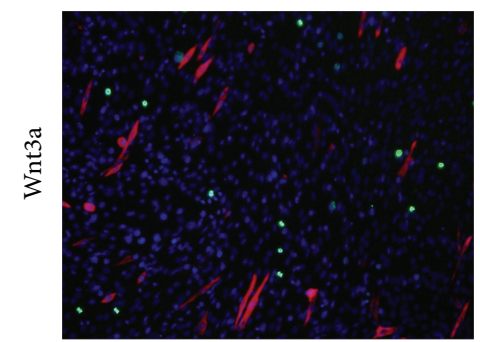

(b)

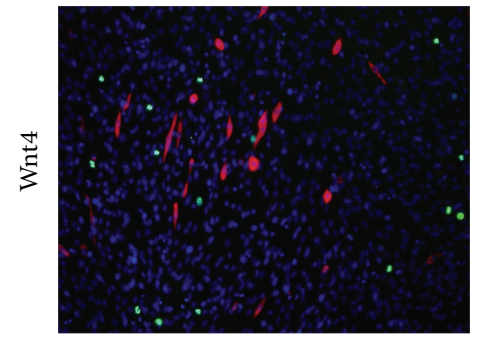

(c)

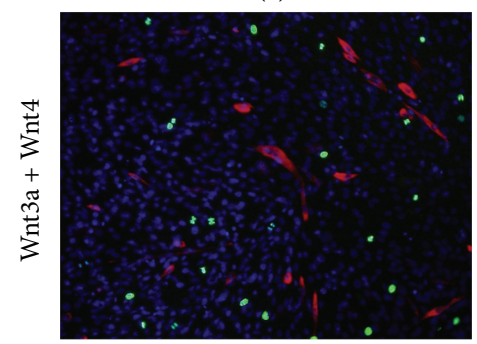

(d)

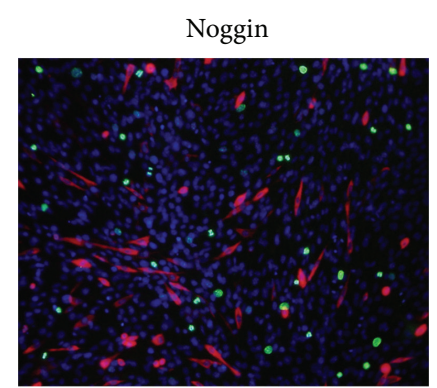

(e)

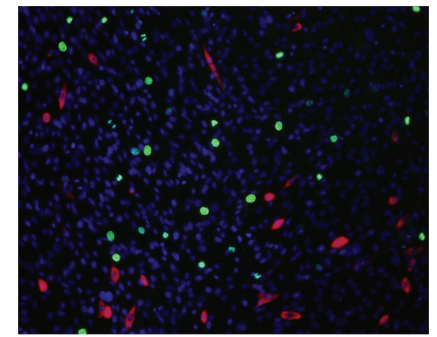

(f)

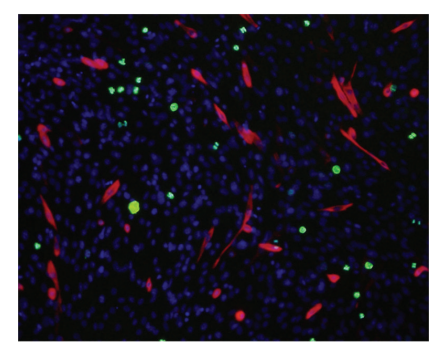

(g)

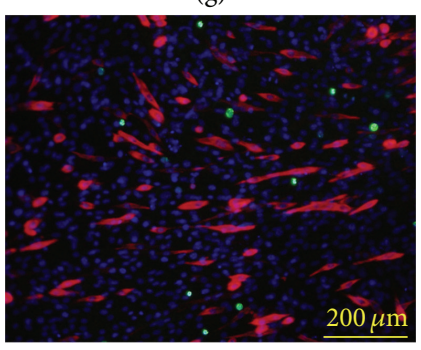

(h)

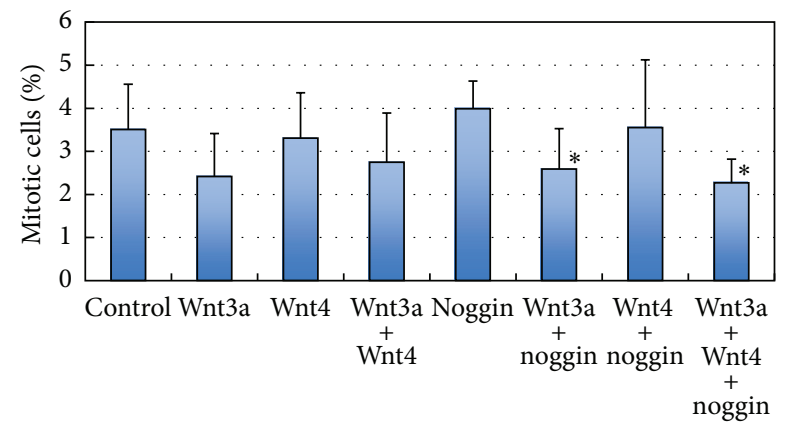

(i)

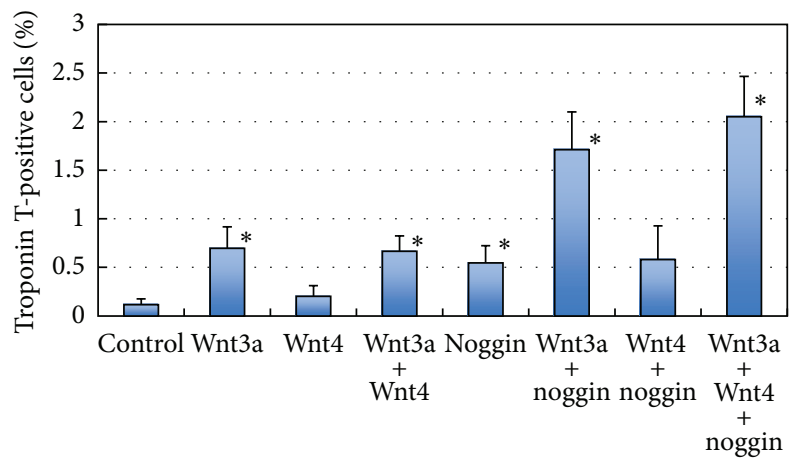

(j)

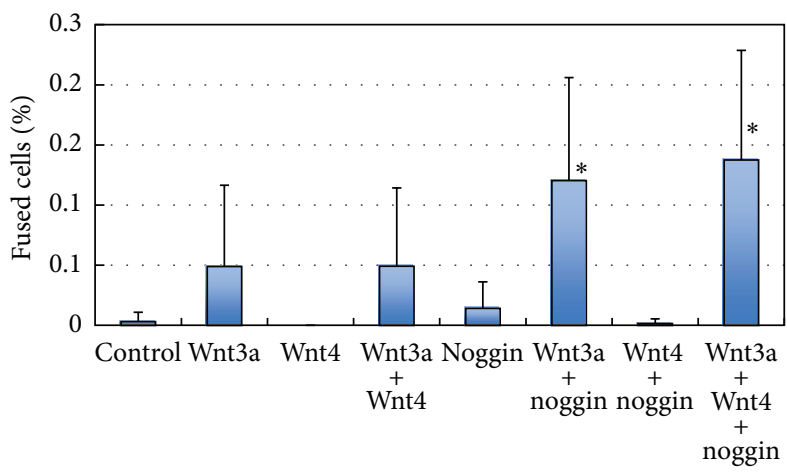

(k)

FiguRE 6: Effect of noggin on troponin T expression with or without Wnt3a and Wnt4. (a-h) The recombinant proteins were added as shown in Figure 3 with final concentrations of $125 \mathrm{ng} / \mathrm{mL}$ Wnt $3 a, 250 \mathrm{ng} / \mathrm{mL}$ Wnt 4 , and $50 \mathrm{ng} / \mathrm{mL}$ noggin, alone or in combination as shown in the figure. Immunohistochemical staining and cell counting were carried out as described in Figure 3 . Addition of noggin elevated troponin $\mathrm{T}$ expression in the presence or absence of Wnt3a and/or Wnt4. (a) Control; (b) Wnt3a; (c) Wnt4; (d) Wnt3a + Wnt4; (e) noggin; (f) Wnt3a + noggin; (g) Wnt4 + noggin; (h) Wnt3a + Wnt4 + noggin. (i-k) The ratios of phosphohistone H3 (i) and troponin T-positive cells (j) to the total cell number were counted. Multinuclear cells expressing troponin $\mathrm{T}(\mathrm{k})$ were also estimated to determine the ratio of fused cells to the total cell number. Mean $+\mathrm{SD}(n=6),{ }^{*} P<0.01$ versus control with Student's $t$-test.

uniform expression of Wnt genes in the target cells [16]. As shown in previous reports, Wnt3a overexpression resulted in elevated proliferation rates in myoblast cells while preventing myogenic differentiation accompanying nuclear localization of $\beta$-catenin, whereas $W n t 4$ overexpression counteracted the effects of $W n t 3 a$, resulting in reduced rates of proliferation and enhanced differentiation [16]. To observe the effects of $\mathrm{BMP} / \mathrm{Smad}$ signaling on $\mathrm{Wnt} / \beta$-catenin signaling, we used adenovirus-mediated expression of Wnt $3 a$ and Wnt4, since viral expression of the Wnt genes resulted in consistent elevation of $\beta$-catenin signaling (Figure 7). When Wnt $3 a$ was overexpressed in $\mathrm{C} 2 \mathrm{C} 12$ cells, troponin $\mathrm{T}$ expression was significantly enhanced compared to control cells expressing eGFP instead of Wnt (Figure 6). On the contrary, Wnt4 expression showed minor effect on myogenic differentiation, as indicated by the increased number of troponin Texpressing cells and of cells fusing to form multinuclear myotubes (Figure 6). When BMP4 and noggin were added to the culture medium after overexpression of Wnt $3 a$ and Wnt4 with adenovirus vectors, $\beta$-catenin signals in $\mathrm{C} 2 \mathrm{C} 12$ 


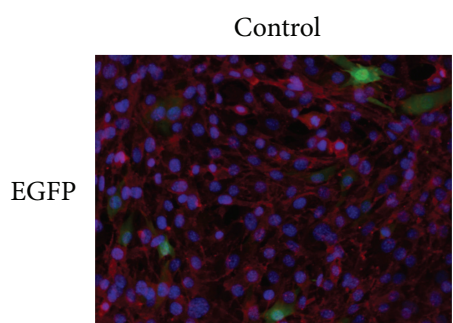

(a)

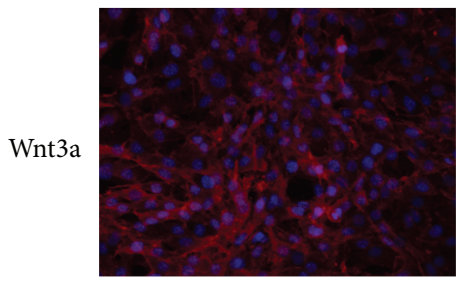

(b)

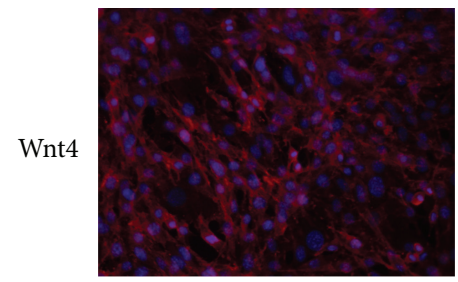

(c)

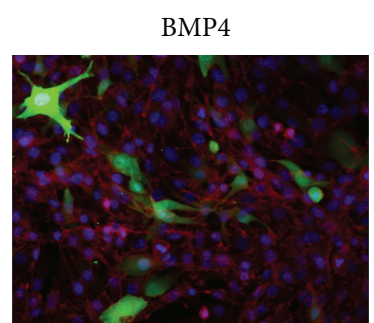

(d)

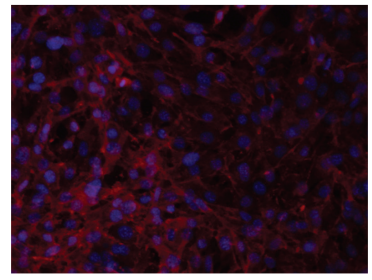

(e)

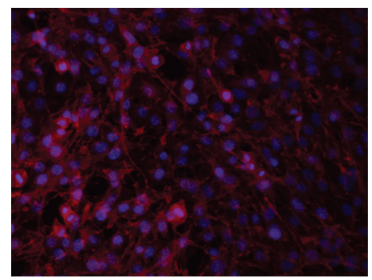

(f)

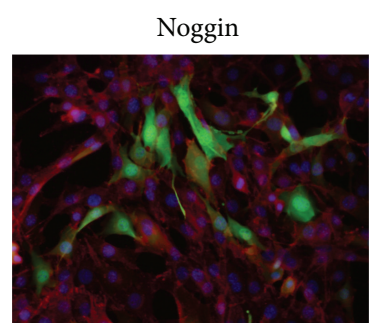

(g)

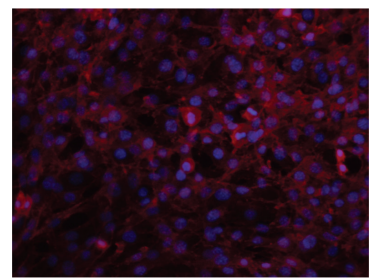

(h)

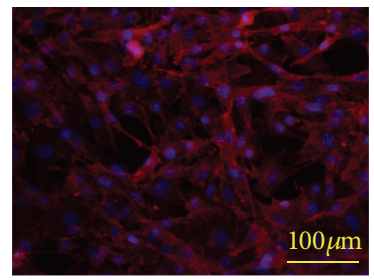

(i)

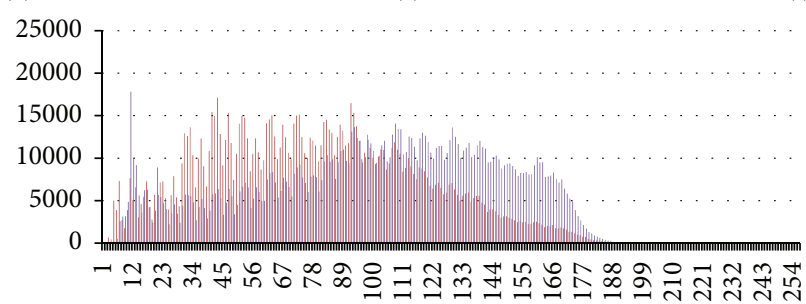

(j)

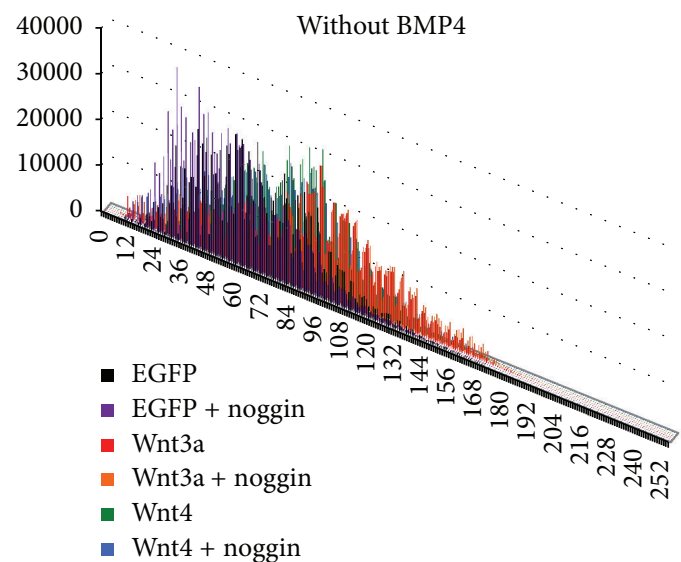

(k)

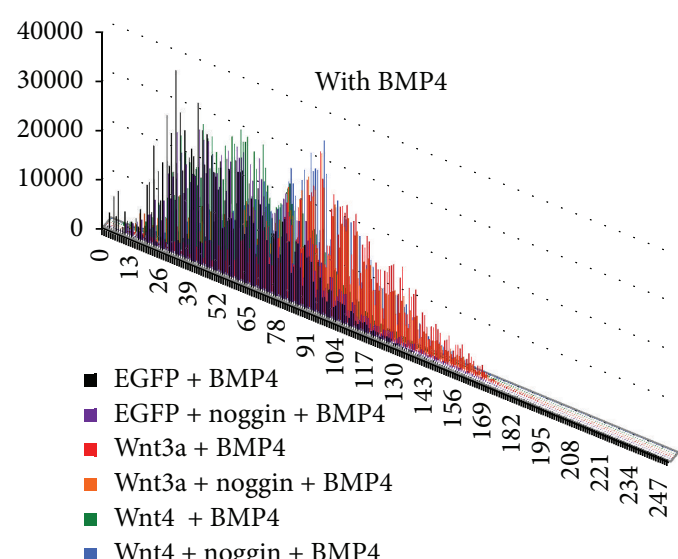

(1)

FIGURE 7: Effects of BMP4 and noggin on $\beta$-catenin localization with or without Wnt3a and Wnt4. (a-i) Recombinant adenoviruses were used to express Wnt3a, Wnt4, or eGFP (control) uniformly in C2C12 cells. Cells were infected 48 hours earlier with an MOI of 400, and the recombinant proteins were added as shown in Figure 3 with final concentrations of $5 \mathrm{ng} / \mathrm{mL}$ BMP 4 and/or $250 \mathrm{ng} / \mathrm{mL}$ noggin. Two hours after BMP4 addition, immunostaining for $\beta$-catenin was carried out for counting. (j) Comparison of the $\beta$-catenin signals after adenovirusmediated expression of Wnt3a and eGFP, after pixel intensity analysis for immunohistochemical signals with BZ-II Analyzer, shown in abscissa for signal intensity and ordinate for frequency. Wnt3a intensified signals to a higher level. (k and 1 ) Comparison of the $\beta$-catenin signals after adenovirus-mediated expression of Wnt $3 a$, Wnt4, and $e G F P$, in the presence or absence of BMP4 and/or noggin. Immunostaining for $\beta$-catenin was analyzed by digitizing the signals with BZ-II Analyzer for comparison. Typical results are shown. (k) Without BMP4; (l) with BMP4. 
cells were not affected (Figure 7), indicating that Wnt $/ \beta$ catenin signaling was not affected or modified by BMP/Smad signaling.

\section{Discussion}

We established Wnt4-expressing cells from C2C12 cells after transfection of an expression construct followed by clonal selection. These cells spontaneously differentiated to form myotubes, characterized by troponin $\mathrm{T}$ and myosin heavy chain expression, even in serum-rich medium. The growth rate of the Wnt4-expressing cells decreased to about half of that of the original cells in proliferation medium, because the Wnt4-overexpressing cells had a tendency to spontaneously differentiate. Thus, the Wnt4-overexpressing cells had the unique phenotype of expressing myosin heavy chain even in the mitogen-containing proliferation medium, in contrast to the previously observed phenotype of $\mathrm{C} 2 \mathrm{C} 12$ cells overexpressing Wnt3a [21]. Wnt4 overexpression appears to override or dominate the regulation of the $\mathrm{C} 2 \mathrm{C} 12$ phenotypes in the proliferation and differentiation states.

Wnt3a overexpression is known to counteract the BMP2induced inhibition of myotube formation in $\mathrm{C} 2 \mathrm{C} 12$ cells switched to low-serum medium, and BMP2-induced Id1 expression was decreased in Wnt $3 a$-expressing cells but not in Wnt5a-expressing cells [21]. BMP2 and BMP4 have identical activity in binding BMP receptors and activate Smad1/5/8 in $\mathrm{C} 2 \mathrm{C} 12$ cells [22], although the induction of differentiation after Wnt4 expression or mitogen deprivation elevated $B M P 4$ but not BMP2 expression. Signaling interaction with Wnt family members resulted in different but overlapping consequences, depending on activation of the canonical or the noncanonical Wnt pathway [23-25].

Wnt 4 was shown to counteract the effect of myostatin on myogenic differentiation either upstream or downstream of the $\operatorname{Smad} 2 / 3$ pathways $[8,11,12,15]$, whereas elevated levels of BMP2/4 resulted in Smad1/5/8 activation and regulated the transition of progenitor cells from a myogenic to an osteogenic cell fate $[22,24,26]$. Signal crosstalk between $\mathrm{BMP} / \mathrm{Smad}$ and Wnt $/ \beta$-catenin is partially implicated in the commitment of myogenic progenitor cells to the formation of myotubes; a functional interaction between the BMP and Wnt families is known in paraxial mesoderm differentiation and cell fate determination during early embryogenesis $[3,5]$. Wnt3a-dependent subcellular localization of $\beta$-catenin plays a role in progenitor cell proliferation as one of the determinants of myogenic cell fate, independent of BMP and noggin $[23,27]$. However, Wnt 4 modified BMP4-dependent Smad1/5 phosphorylation, suggesting that noncanonical Wnt signaling plays a role in BMP2/4-dependent signaling during myogenic differentiation, and functional Notch signaling may be implicated in this process [28]. However, discrepancy on Smad1/5 phosphorylation after Wnt3a and Wnt4 expression is not simply interpreted at present in terms of BMP4-induced Smad1/5 phosphorylation, suggesting indirect interaction between BMP/Smad signaling and Wnt signaling. Although calcium signaling is crucial in myoblast differentiation, there is no evidence in $\mathrm{C} 2 \mathrm{C} 12$ cells whether noncanonical Wnt4 plays a role in calcium signaling as known for Wnt5a [1-3].

Noggin is a BMP-binding protein that antagonizes Smad1/5/8 phosphorylation at the transmembrane receptor complexes and can stimulate muscle differentiation through antagonism of endogenous BMPs. This effect of noggin was enhanced in the presence of Wnt3a and Wnt 4 . Since the $\mathrm{Wnt} / \beta$-catenin pathway was not modified by BMP/Smad signaling during the transition from progenitor cell proliferation to myogenic differentiation, direct signal crosstalk is unlikely and probably independently regulated. BMP4/Smad signaling is presumed to counteract Wnt4-promoted myogenic differentiation. However, a positive correlation was found between noncanonical Wnt4 signaling and BMP4-induced Smad1/5 phosphorylation. Wnt 4 was shown to counteract Wnt3a in myoblast differentiation [16], and Wnt4, but not Wnt3a, potentiated BMP4-dependent Smad1/5 phosphorylation, suggesting that noncanonical Wnt 4 signaling is involved in myogenic differentiation in concert with Wnt3a/ $\beta$-catenin.

\section{Conclusions}

Wnt $/ \beta$-catenin signaling is involved in various aspects of skeletal muscle development and regeneration [7-9]. The characterization of signaling interactions provides insights for the development of therapeutics for regenerative medicine based on the fundamental cascades during myogenic proliferation and differentiation. Our results suggest that noncanonical Wnt signaling interacts with BMP signaling through the regulation of $S$ mad1/5 phosphorylation and acts in addition to $\mathrm{Wnt} / \beta$-catenin signaling in myogenic turnover.

\section{Methods}

5.1. Cell Culture and Cloning of Wnt4-Expressing Transfectants. The $\mathrm{C} 2 \mathrm{C} 12$ cell line (myoblast-like cell line from the $\mathrm{C} 3 \mathrm{H}$ mouse) was purchased from the RIKEN Cell Bank (RIKEN, Wako, Japan) and cultured in Dulbecco's modified Eagle's medium (DMEM) supplemented with 10\% fetal bovine serum (FBS, Nichirei Corp., Tokyo). After 12 to $24 \mathrm{~h}$ of subculture, cells were transfected with an expression vector bearing V5-tagged Wnt4 cDNA $\left(\mathrm{P}_{\mathrm{CMV}}\right.$-Wnt4V5- $\mathrm{P}_{\mathrm{PGK}}$-blasticidin-SV40pA). Transfected C2C12 cells were cultured in DMEM containing 10\% FBS and blasticidin (Life Technologies Co.). Fourteen clones were selected and about half of them were used for further analysis. Wnt4-expressing stable transfectants were obtained after serial passages in selection medium containing blasticidin for 4 to 5 weeks.

5.2. Expression Analysis. Transcriptome analysis was carried out using total RNA extracted from $\mathrm{C} 2 \mathrm{C} 12$ cells under proliferation or differentiation conditions, and the results were compared between parental and Wnt4-expressing C2C12derived cells. Cells were grown either in proliferation medium containing 10\% FBS in DMEM or in differentiation medium containing $2 \%$ horse serum (Sigma-Aldrich) in DMEM and cultured for two days in $100 \mathrm{~mm}$ diameter dishes. Total RNA was extracted from cultured cells using 
Isogen (Nippon Gene Co., Tokyo, Japan) according to the manufacturer's instructions. Expression profiles were examined under the following conditions: $\mathrm{C} 2 \mathrm{C} 12$ proliferating in rich medium; $\mathrm{C} 2 \mathrm{C} 12$ differentiating in poor medium; Wnt4-overexpressing $\mathrm{C} 2 \mathrm{C} 12$ cell line proliferating in rich medium. Labeling, hybridization, scanning, and data processing were carried out with Toray 3D Gene (Toray Industries, Inc., Tokyo). Minimum information about a microarray experiment-(MIAME-) compliant array data including raw data is deposited in the Gene Expression Omnibus (GEO) at NCBI with accession number GSE40456.

5.3. Recombinant Virus Preparation and Treatment. Adenoviruses carrying Wnt cDNAs were prepared using the ViraPower Adenovirus Expression System (Life Technologies Co.), and recombinant adenoviruses expressing $W n t 3 a$, Wnt4, and eGFP cDNAs were constructed as described previously [16]. In brief, 293A cells were used to propagate recombinant adenovirus until the viral titer reached about $10^{9} \mathrm{pfu} / \mathrm{mL}$. C2C12 cells were infected with a multiplicity of infection (MOI) of 400 because of poor infection efficiency in $\mathrm{C} 2 \mathrm{C} 12$ cells. Recombinant Wnt3a, Wnt4, and noggin Fc chimera were obtained from R\&D Systems through Cosmo Bio Co., Ltd. (Tokyo, Japan), recombinant BMP4 was obtained from HumanZyme (Chicago, IL, USA), and the recombinant proteins were used according to the manufacturers' recommendations. An adenovirus vector expressing eGFP was used as a negative control for virally mediated transgene expression, and green fluorescence was monitored to estimate transgene expression.

5.4. Immunofluorescence Detection. Cells were fixed in phosphate-buffered saline (PBS) containing 4\% paraformaldehyde. After three washes with PBS, cells were immunohistochemically stained as previously described [16], using anti-fast myosin heavy chain (M4276, SigmaAldrich, Saint Louis, MO, USA), anti-slow myosin heavy chain (M8421, Sigma-Aldrich), anti-troponin T (MAB1487, clone TT-98, Abnova, Walnut, CA, USA), anti- $\beta$-catenin (C2206, Sigma-Aldrich), anti-phospho-Smad1/5, and anti-phospho- (Ser10) histone H3 (382159, Calbiochem, Millipore) antibodies at 1:100, 1:200, 1:40, 1:200, 1:1000, and 1:500 dilutions, respectively. After washing, cells were incubated with a 1:250 dilution of secondary Alexa Fluor 594- or 488-conjugated goat anti-mouse or anti-rabbit IgG antibodies (A11032, A11037, A11029, Molecular Probes, Invitrogen, Carlsbad, CA, USA). Cell nuclei were stained with $1 \mu \mathrm{g} / \mathrm{mL} 4^{\prime}, 6^{\prime}$-diamino-2-phenylindole solution (DAPI, Dojindo, Kumamoto, Japan). Fluorescent images were taken using an All-in-One Fluorescence Microscope BZ-9000 (Keyence, Osaka, Japan). Statistical significance of the immunostained cell number was evaluated with Student's $t$-test.

\section{Conflict of Interests}

All authors declare that no conflict of interests exists in the present work.

\section{Authors' Contribution}

Kumiko Terada, Naoki Katase, Shin-ichiro Nishimatsu, and Tsutomu Nohno conceived and designed the experiments; Kumiko Terada and Satomi Misao performed the experiments and analyzed the data; Tsutomu Nohno prepared the paper.

\section{Acknowledgments}

The authors thank Yayoi Kubota for excellent technical assistance. This work was supported by a Grant-in-Aids for Scientific Research (C) from the Japan Society for the Promotion of Science (23590227), and by Research Project grants from Kawasaki Medical School (23-T1, 23-D1).

\section{References}

[1] “The Wnt Homepage," http://www.stanford.edu/group/nusselab/ cgi-bin/wnt/.

[2] R. van Amerongen and R. Nusse, "Towards an integrated view of Wnt signaling in development," Development, vol. 136, no. 19, pp. 3205-3214, 2009.

[3] R. Nusse and X. He, Eds., Wnt Signaling, Cold Spring Harbor Laboratory Press, New York, NY, USA, 2013.

[4] Y. Yang, "Wnt signaling in development and disease," Cell \& Bioscience, vol. 2, article 14, 2012.

[5] N. Itasaki and S. Hoppler, "Crosstalk between Wnt and bone morphogenic protein signaling: a turbulent relationship," Developmental Dynamics, vol. 239, no. 1, pp. 16-33, 2010.

[6] I. Kozmikova, J. Smolikova, C. Vlcek, and Z. Kozmik, "Conservation and diversification of an ancestral chordate gene regulatory network for dorsoventral patterning," PLoS One, vol. 6, no. 2, Article ID e14650, 2011.

[7] J. Von Maltzahn, N. C. Chang, C. F. Bentzinger, and M. A. Rudnicki, "Wnt signaling in myogenesis," Trends in Cell Biology, vol. 22, no. 11, pp. 602-609, 2012.

[8] Y. Fedon, A. Bonnieu, S. Gay, B. Vernus, F. Bacou, and H. Bernardi, "Role and function of Wnts in the regulation of myogenesis: when Wnt meets myostatin," in Skeletal MuscleFrom Myogenesis to Clinical Relations, J. Cseri, Ed., chapter 4, 2012.

[9] A. Otto, C. Schmidt, G. Luke et al., "Canonical Wnt signalling induces satellite-cell proliferation during adult skeletal muscle regeneration," Journal of Cell Science, vol. 121, no. 17, pp. 29392950, 2008.

[10] J. Von Maltzahn, C. F. Bentzinger, and M. A. Rudnicki, "Wnt7aFzd7 signalling directly activates the Akt/mTOR anabolic growth pathway in skeletal muscle," Nature Cell Biology, vol. 14, no. 2, pp. 186-191, 2012.

[11] C. A. Steelman, J. C. Recknor, D. Nettleton, and J. M. Reecy, "Transcriptional profiling of myostatin-knockout mice implicates Wnt signaling in postnatal skeletal muscle growth and hypertrophy," FASEB Journal, vol. 20, no. 3, pp. 580-582, 2006.

[12] H. Takata, K. Terada, H. Oka, Y. Sunada, T. Moriguchi, and T. Nohno, "Involvement of Wnt4 signaling during myogenic proliferation and differentiation of skeletal muscle," Developmental Dynamics, vol. 236, no. 10, pp. 2800-2807, 2007.

[13] P. Bernard, A. Fleming, A. Lacombe, V. R. Harley, and E. Vilain, "Wnt4 inhibits $\beta$-catenin/TCF signalling by redirecting 
$\beta$-catenin to the cell membrane," Biology of the Cell, vol. 100, no. 3, pp. 167-177, 2008.

[14] J.-M. Tee, C. van Rooijen, R. Boonen, and D. Zivkovic, "Regulation of slow and fast muscle myofibrillogenesis by Wnt/ $\beta$ catenin and myostatin signaling," PLoS One, vol. 4, no. 6, Article ID e5880, 2009.

[15] H. Bernardi, S. Gay, Y. Fedon, B. Vernus, A. Bonnieu, and F. Bacou, "Wnt4 activates the canonical $\beta$-catenin pathway and regulates negatively myostatin: functional implication in myogenesis," American Journal of Physiology, vol. 300, no. 5, pp. C1122-C1138, 2011.

[16] S. Tanaka, K. Terada, and T. Nohno, "Canonical Wnt signaling is involved in switching from cell proliferation to myogenic differentiation of mouse myoblast cells," Journal of Molecular Signaling, vol. 6, article 12, 2011.

[17] T. Nohno, T. Ishikawa, T. Saito et al., "Identification of a human type II receptor for bone morphogenetic protein- 4 that forms differential heteromeric complexes with bone morphogenetic protein type I receptors," Journal of Biological Chemistry, vol. 270, no. 38, pp. 22522-22526, 1995.

[18] A. Yamaguchi, "Regulation of differentiation pathway of skeletal mesenchymal cells in cell lines by transforming growth factor$\beta$ superfamily," Seminars in Cell and Developmental Biology, vol. 6, no. 3, pp. 165-173, 1995.

[19] W. E. Taylor, S. Bhasin, J. Artaza et al., "Myostatin inhibits cell proliferation and protein synthesis in $\mathrm{C} 2 \mathrm{C} 12$ muscle cells," American Journal of Physiology, vol. 280, no. 2, pp. E221-E228, 2001.

[20] T. Katagiri, S. Akiyama, M. Namiki et al., "Bone morphogenetic protein-2 inhibits terminal differentiation of myogenic cells by suppressing the transcriptional activity of MyoD and myogenin," Experimental Cell Research, vol. 230, no. 2, pp. 342-351, 1997.

[21] A. Nakashima, T. Katagiri, and M. Tamura, "Cross-talk between Wnt and bone morphogenetic protein 2 (BMP-2) signaling in differentiation pathway of $\mathrm{C} 2 \mathrm{C} 12$ myoblasts," Journal of Biological Chemistry, vol. 280, no. 45, pp. 37660-37668, 2005.

[22] N. Yamamoto, S. Akiyama, T. Katagiri, M. Namiki, T. Kurokawa, and T. Suda, "Smad1 and smad5 act downstream of intracellular signalings of BMP-2 that inhibits myogenic differentiation and induces osteoblast differentiation in C2C12 myoblasts," Biochemical and Biophysical Research Communications, vol. 238, no. 2, pp. 574-580, 1997.

[23] H. Petropoulos and I. S. Skerjanc, " $\beta$-catenin is essential and sufficient for skeletal myogenesis in P19 cells," Journal of Biological Chemistry, vol. 277, no. 18, pp. 15393-15399, 2002.

[24] M. Friedrichs, F. Wirsdöerfer, S. B. Flohé, S. Schneider, M. Wuelling, and A. Vortkamp, "BMP signaling balances proliferation and differentiation of muscle satellite cell descendants," BMC Cell Biology, vol. 12, article 26, 2011.

[25] Y. Wang, J. S. Mohamed, and S. E. Alway, "M-cadherininhibited phosphorylation of $\beta$-catenin augments differentiation of mouse myoblasts," Cell and Tissue Research, vol. 351, pp. 183-200, 2013.

[26] J. Nojima, K. Kanomata, Y. Takada et al., "Dual roles of Smad proteins in the conversion from myoblasts to osteoblastic cells by bone morphogenetic proteins," Journal of Biological Chemistry, vol. 285, no. 20, pp. 15577-15586, 2010.

[27] X. H. Han, Y.-R. Jin, M. Seto, and J. K. Yoon, "A WNT/ $\beta$-catenin signaling activator, R-spondin, plays positive regulatory roles during skeletal myogenesis," Journal of Biological Chemistry, vol. 286, no. 12, pp. 10649-10659, 2011.
[28] C. Dahlqvist, A. Blokzijl, G. Chapman et al., "Functional Notch signaling is required for BMP4-induced inhibition of myogenic differentiation," Development, vol. 130, no. 24, pp. 6089-6099, 2003. 

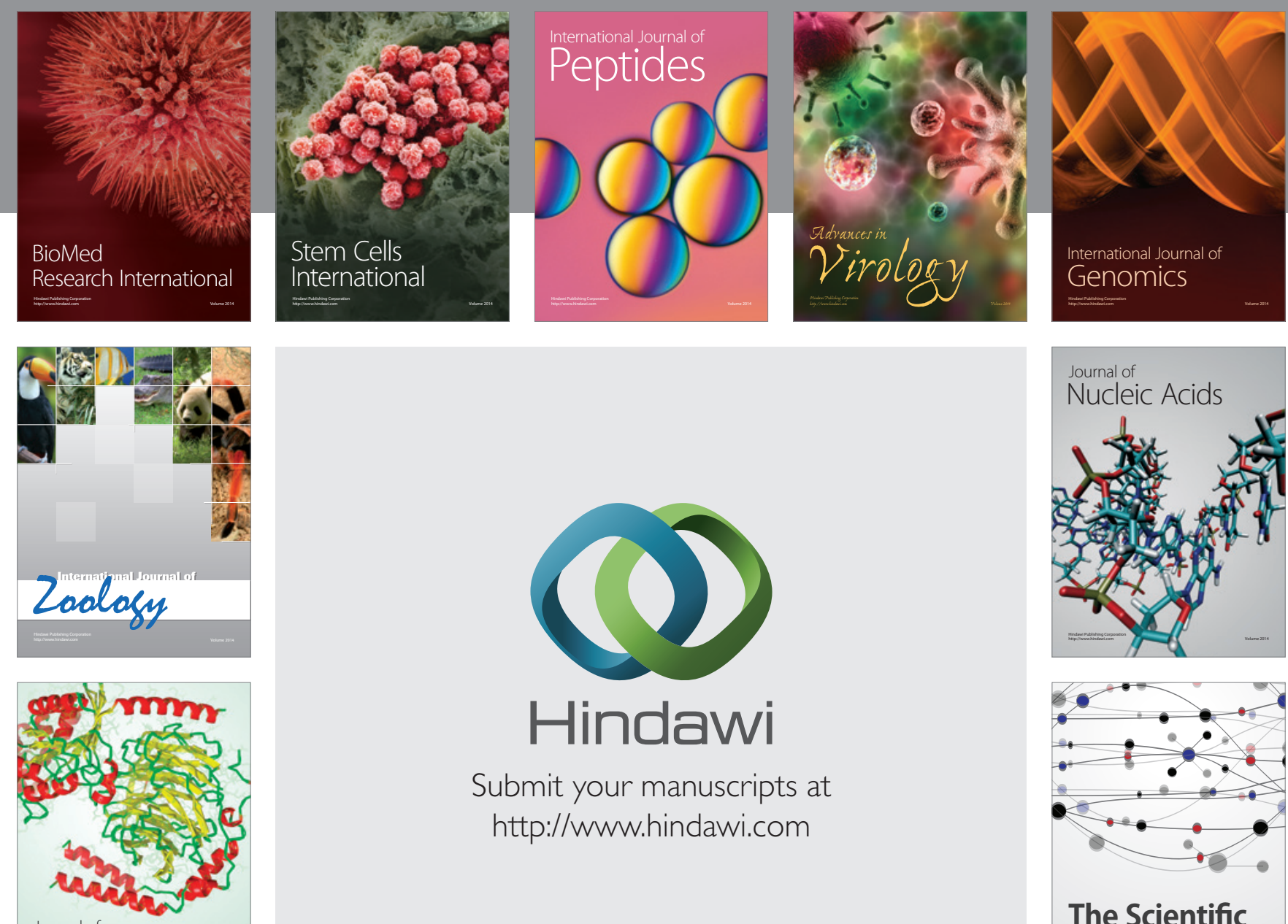

Submit your manuscripts at

http://www.hindawi.com

Journal of
Signal Transduction
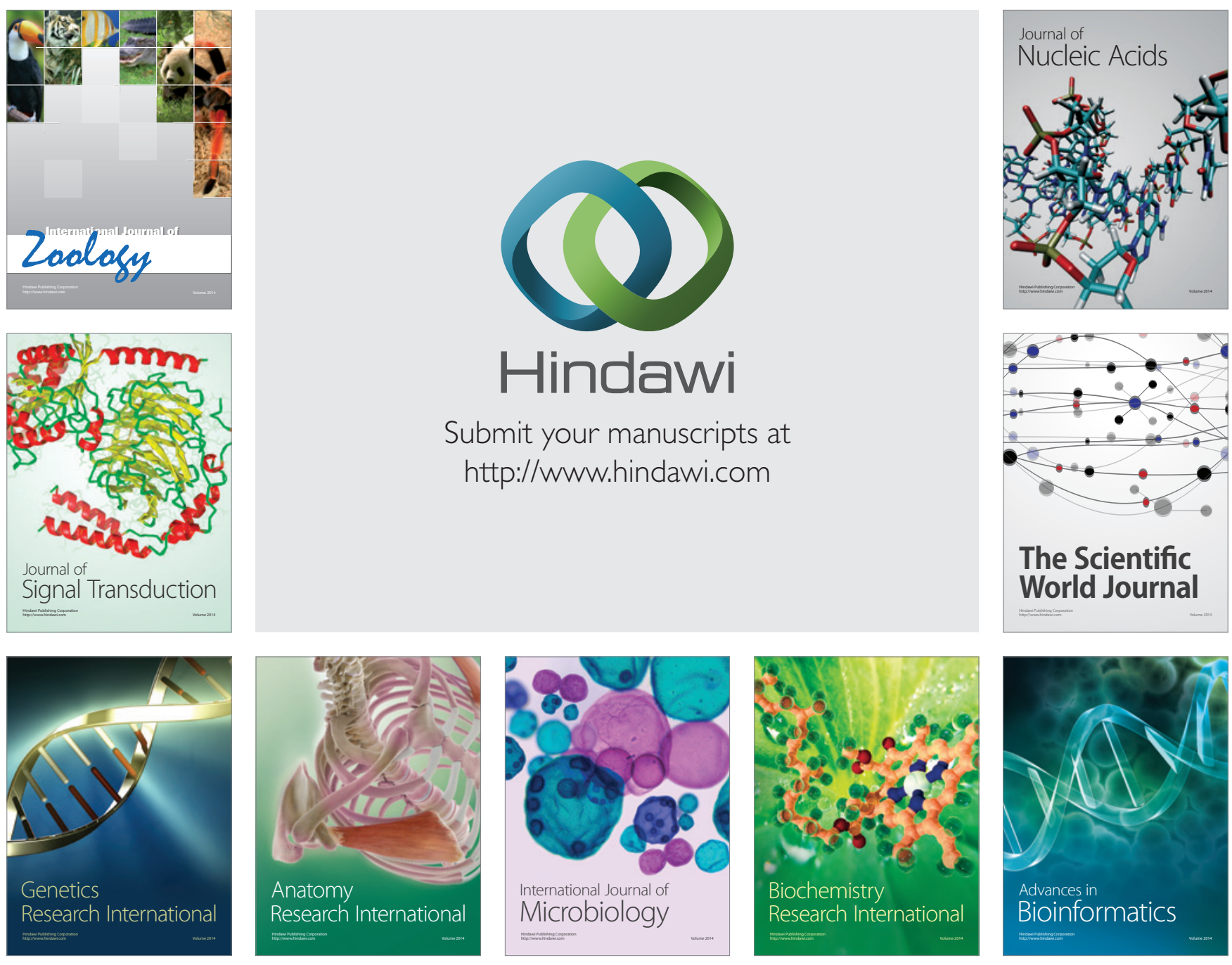

The Scientific World Journal
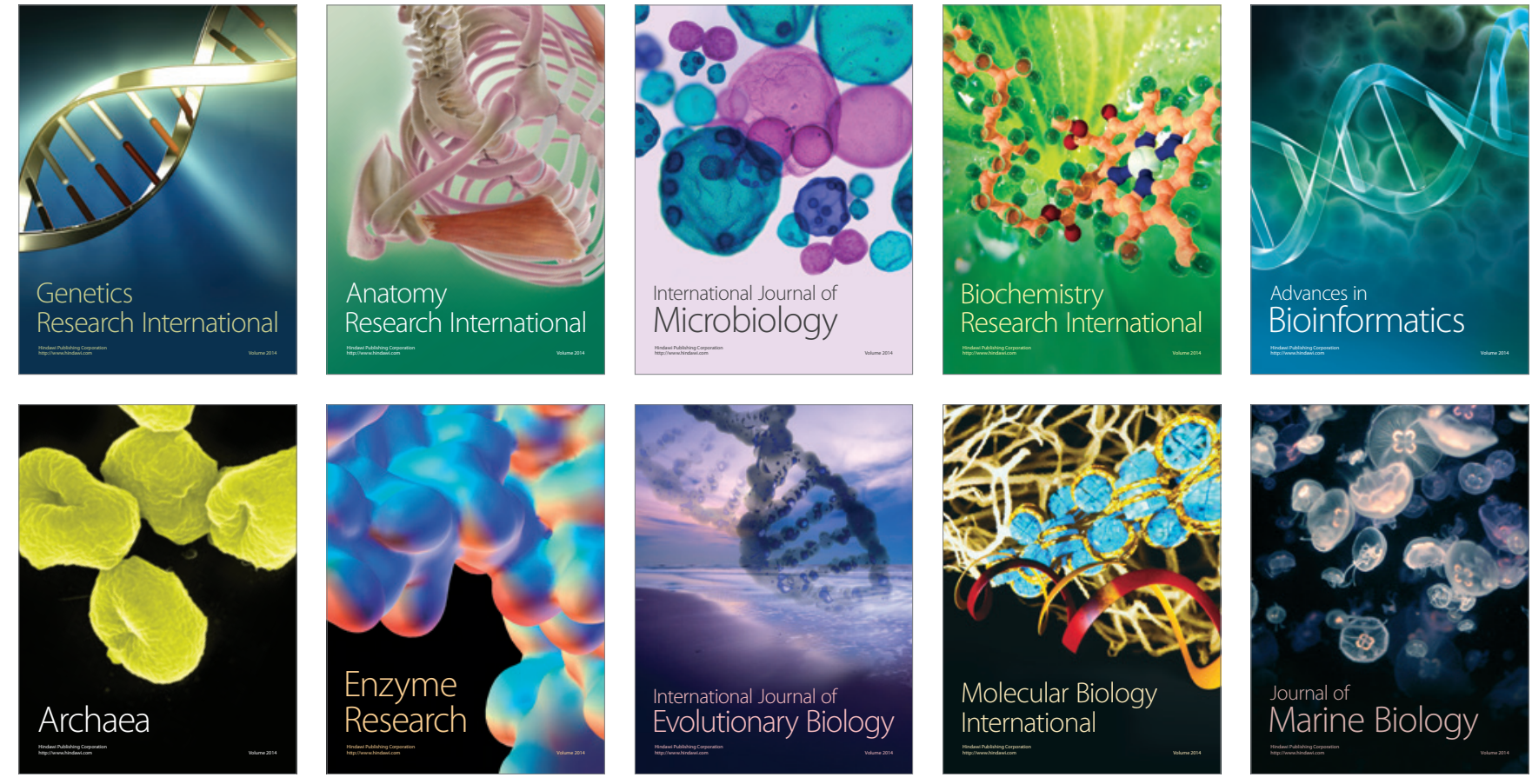